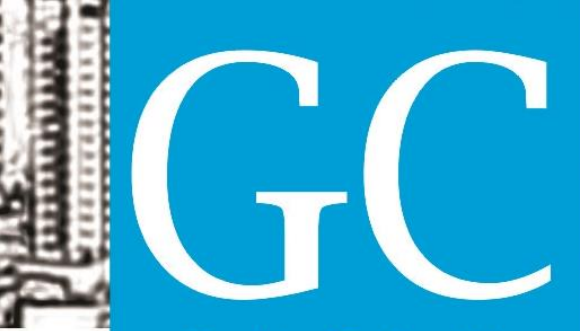

Revista Nacional de Gerenciamento de Cidades

\title{
INSTRUMENTOS DE ACESSIBILIDADE: UMA ANÁLISE SOBRE AS RAMPAS DE ACESSO NA CIDADE DE ITUIUTABA - MG
}

\author{
Daniel de Araujo Silva ${ }^{1}$
}

Carlos Roberto Loboda ${ }^{2}$

\begin{abstract}
RESUMO
A presente pesquisa teve por objetivo principal realizar uma análise qualitativa e quantitativa das rampas de acesso no centro da cidade de Ituiutaba-MG. Do ponto de vista teórico, buscamos fundamentar nossa reflexão acerca da temática abordada, visando à fundamentação necessária para uma melhor articulação entre teoria e empiria. Para avaliar as rampas de acesso, utilizou-se como base norteadora, os procedimentos de observação, análise e comparação, principalmente tendo como parâmetro as normas recomendadas pela ABNT através da NBR 9050/2004. Os resultados obtidos apontam para o fato de que na cidade de Ituiutaba - $M G$ as condições adequadas de acessibilidade são mínimas e o descaso acompanha essa constatação, nem todas as esquinas e cruzamentos possuem rampas de acesso ou guias rebaixadas, ocorrendo uma descontinuidade. Em nenhuma delas encontramos sinalização tátil, e a maioria não está em conformidade com as faixas de pedestres, além de não seguirem nenhum padrão e normas recomendadas pela ABNT, e a maioria delas se encontram péssimas em condições estruturais. Diante dos resultados aqui evidenciados, espera-se que, o poder público desenvolva projetos voltados para a acessibilidade, implantando instrumentos e equipamentos, e/ou reformando ou adaptando os já existentes dentro dos padrões e normas, para que assim, garantam o acesso das pessoas ao espaço urbano de forma mais igualitária.
\end{abstract}

PALAVRAS-CHAVE: Acessibilidade; Espaço Público; Ituiutaba-MG.

\footnotetext{
${ }^{1}$ Graduando em Geografia pela Faculdade de Ciências Integradas do Pontal (FACIP), Universidade Federal de Uberlândia (UFU). Silva.d.a@live.com

${ }^{2}$ Orientador da Pesquisa - Professor do Curso de graduação em Geografia - FACIP/UFU.

Loboda@pontal.ufu.br
} 


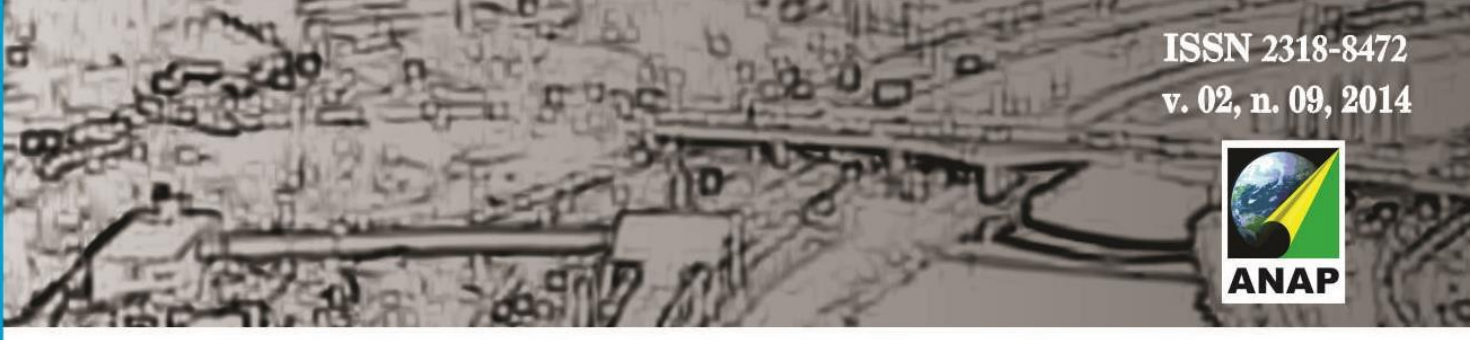

Revista Nacional de

Gerenciamento de Cidades

\title{
INSTRUMENTS OF ACCESSIBILITY: AN ANALYSIS ON THE RAMPS IN THE CITY OF ACCESS ITUIUTABA - MG
}

\begin{abstract}
The present work had as main objective to analyze a qualitative and quantitative analysis of access ramps in the town center of Ituiutaba-MG. From the theoretical point of view, we seek to support our reflection on the themes addressed, seeking the necessary basis for a better articulation between theory and empiricism. To evaluate the access ramps, was used as a guiding basis, the procedures of observation, analysis and comparison, mainly based on the parameters recommended by the ABNT NBR through 9050/2004 standards. The results point to the fact that the city of Ituiutaba appropriate accessibility conditions are minimal and the neglect accompanies this realization, not all corners and intersections have ramps or recessed tabs, causing a discontinuity. In none of them found tactile signage, and most are not in accordance with the crosswalks, and do not follow any pattern and recommended by ABNT standards, and most of them are in bad structural conditions. Given the results shown here, it is expected that the government develop projects for accessibility, deploying instruments and equipment, and / or renovating or adapting existing within the standards and norms, so that thus ensuring people's access the urban space more equally.
\end{abstract}

KEY-WORDS: Accessibility; Public Space; Ituiutaba-MG.

\section{INSTRUMENTOS DE ACCESIBILIDAD: ANÁLISIS SOBRE LAS RAMPAS DE ACCESO EN LA CIUDAD DE ITUIUTABA-MG}

\section{RESUMEN}

El presente estudio tiene como objetivo proporcionar un análisis cualitativo y cuantitativo de las rampas de acceso en el centro de la ciudad de Ituiutaba-MG. Del punto de vista teórico, se busca una base para nuestra reflexión sobre el tema abordado, con el objetivo de razonamiento necesario para una mejor articulación entre la teoría y empirismo. Para evaluar las rampas de acceso, se utilizó como base de guía, los procedimientos de observación, el análisis y la comparación, basada principalmente en los parámetros recomendados por la ABNT NBR través 9050/2004 normas. Los resultados apuntan al hecho de que la ciudad de Ituiutaba - MG condiciones de accesibilidad adecuada son mínimos y la negligencia acompaña esta realización, no todas las esquinas e intersecciones tienen rampas o lengüetas empotradas, provocando una discontinuidad. En ninguno de ellos se encuentra la señalización táctil, y la mayoría no están de acuerdo con los pasos de peatones, y no siguen ningún patrón y recomendado por las normas de la ABNT, y la mayoría de ellos se encuentran en malas condiciones estructurales. Teniendo en cuenta los resultados que se muestran aquí, se espera que el gobierno a desarrollar proyectos para la accesibilidad, la implementación de los instrumentos y equipos, y / o renovar o adaptar las existentes dentro de las reglas y normas, de manera que lo que garantiza el acceso de las personas el espacio urbano de manera más equitativa.

PALABRAS-CLAVE: Accesibilidad; Espacio Público; Ituiutaba-MG. 
Revista Nacional de Gerenciamento de Cidades

diretrizes da Política Nacional de Mobilidade Urbana, regida pela Lei № 12.587, de 3 de janeiro de 2012, define que: "Mobilidade Urbana é a condição em que se realizam os deslocamentos de pessoas e cargas no espaço urbano" e também se define que "acessibilidade é a facilidade disponibilizada às pessoas que possibilite a todos autonomia nos deslocamentos desejados, respeitando-se a legislação em vigor" (BRASIL, 2012, p. 2).

Assim, para assegurar o pleno deslocamento e o acesso ao espaço urbano, "a mobilidade e a acessibilidade urbana devem ser trabalhadas de forma integrada a fim de garantir uma cidade sustentável e inclusiva" (RIBEIRO FILHO; ALVES; ALVES, 2012, p. 165), e ainda sobre a importância desse par, Santos, F. O. (2012, p. 184) argumenta que "acessibilidade e a mobilidade estão atreladas, pois o uso dos serviços e equipamentos de uma cidade pode ser prejudicado se a mobilidade para as diferentes áreas não for eficaz, o que dependerá do transporte utilizado pelas pessoas".

De acordo com o Ministério das Cidades (2005), mobilidade urbana é:

[...] um atributo das cidades e se refere à facilidade de deslocamentos de pessoas e bens no espaço urbano. Tais deslocamentos são feitos através de veículos, vias e toda a infra-estrutura (vias, calçadas, etc.) que possibilitam esse ir e vir cotidiano. Isso significa que a mobilidade urbana é mais do que o que chamamos de transporte urbano, ou seja, mais do que o conjunto de serviços e meios de deslocamento de pessoas e bens. É o resultado da interação entre os deslocamentos de pessoas e bens com a cidade. Por exemplo, a disponibilidade de meios (automóveis, ônibus, metrôs, bicicletas, etc.) e infra-estrutura adequados para os deslocamentos de pessoas e bens numa área da cidade, pode ajudar a desenvolver tal área. Do mesmo modo, uma área que se desenvolve, vai necessitar de meios e infra-estrutura adequados para os deslocamentos das pessoas e bens naquele local (BRASIL, 2005, p.3).

Vasconcellos (1996) se refere à mobilidade como sendo:

Um atributo associado a pessoas e aos bens; corresponde às diferentes respostas dadas por indivíduos e agentes econômicos às necessidades de deslocamento, considerando-se as dimensões do espaço urbano e a complexidade das atividades nele desenvolvidas. Face à mobilidade os indivíduos podem ser pedestres, ciclistas, usuários de transportes coletivos 


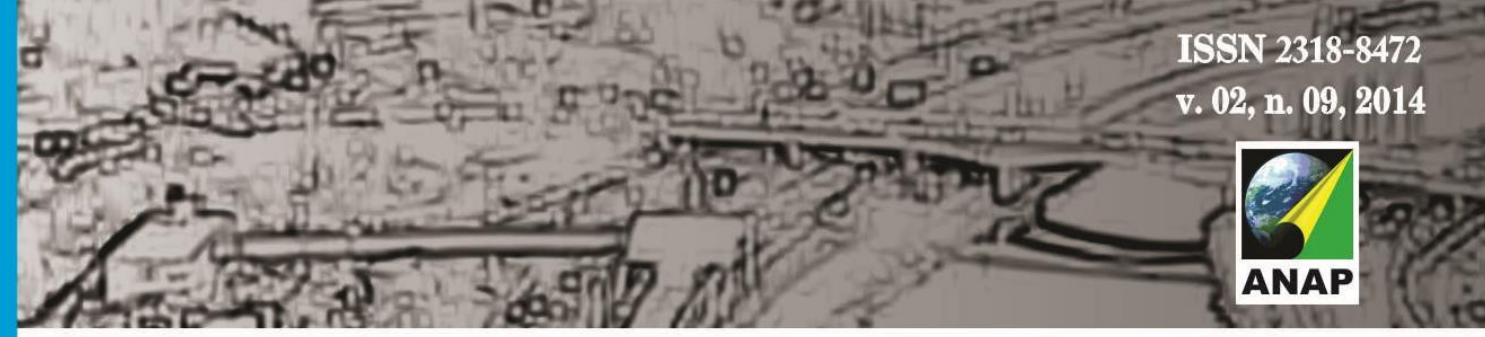

Revista Nacional de

Gerenciamento de Cidades

ou motorista; podem utilizar-se do seu esforço direto (deslocamento a pé) ou recorrer a meios de transporte não motorizados (bicicletas, carroças, cavalos) e motorizados (coletivos e individuais) (VASCONCELLOS, 1996, p. 48)

A Acessibilidade pode ser entendida e concebida sob diversos olhares. $O$ Ministério das Cidades (2006) diz que falar de acessibilidade, em termos gerais, é:

Garantir a possibilidade do acesso, da aproximação, da utilização e do manuseio de qualquer ambiente ou objeto. Reportar este conceito às pessoas com deficiência também está ligado ao fator deslocamento e aproximação do objeto ou local desejado. Indica a condição favorável de um determinado veículo condutor que, neste caso, é o próprio indivíduo, dentro de suas capacidades individuais de se movimentar, locomover e atingir o destino planejado. (BRASIL, 2006, p. 18).

Quanto a Acessibilidade, Ribeiro Filho; Alves; Alves (2012) ressaltam que o tema:

Nos remete a uma reflexão profunda sobre a cidade em todos os seus aspectos, com destaque para a infraestrutura viária, modos de transportes, edificações, mobiliários e equipamentos urbanos, os quais devem possibilitar que as pessoas usufruam da cidade de maneira igualitária, tendo acesso a todos os bens e serviços (RIBEIRO FILHO; ALVES; ALVES, 2012, p. 166).

Assim, no sentido da circulação pelo espaço público urbano, a acessibilidade é a condição para pessoas, sejam elas com mobilidade reduzida ou não, de se deslocarem pela cidade com segurança e independência, livre de obstáculos. As rampas de acesso, são instrumentos de acessibilidade que auxiliam os cadeirantes em sua circulação, portanto, o espaço urbano deve ser dotado dessa estrutura, para garantir que as pessoas exerçam seu direito de "ir e vir" sem interrupções.

\section{DESENVOLVIMENTO}

Um dos problemas que interferem na circulação das pessoas pelas calçadas é a falta de rebaixamentos nas guias ou rampas de acesso. Sem estas, a travessia ou o acesso a determinados locais pelo cadeirante e pessoas como mobilidade reduzida, se torna muito complicada, interferindo na independência das pessoas 


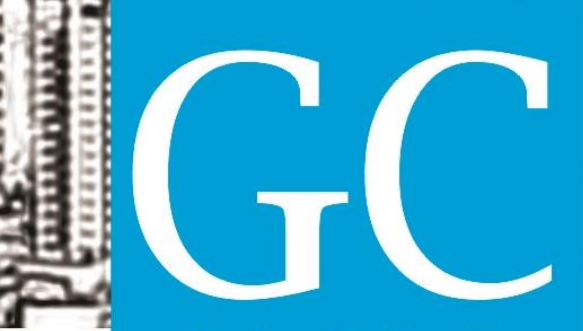

\section{Revista Nacional de}

Gerenciamento de Cidades

quanto a sua circulação, tendo as vezes que contar com a ajuda de terceiros para conseguir fazer sua travessia. Desta forma, as rampas são de suma importância para garantir a acessibilidade nas vias de circulação.

De acordo com a ABNT NBR 9050 (2004), os rebaixamentos de calçadas podem ser feitos tanto em esquinas como nos meios de calçadas e canteiros divisores de pista, e adaptados de acordo com a largura e comprimento das calçadas. Os rebaixamentos nas calçadas, com 2,00 m, devem ter no mínimo 1,20 $\mathrm{m}$ de largura na rampa principal e abas laterais de largura mínima de 0,50 $\mathrm{m}$, tendo remanescente uma largura mínima da calçada de 0,80 m livres. Os rebaixamentos das calçadas localizados em lados opostos devem estar alinhados entre si e às faixas de travessia de pedestres.

Na presente pesquisa, percorremos as ruas do centro da cidade com o intuito de quantificar e qualificar todas as rampas existentes. Primeiramente, através de registro fotográfico e observação, foi realizada uma análise quanto as condições atuais das rampas de acesso e posteriormente foi realizado um mapeamento (Figura 2). A partir desses procedimentos podemos discutir as condições dessas rampas. 


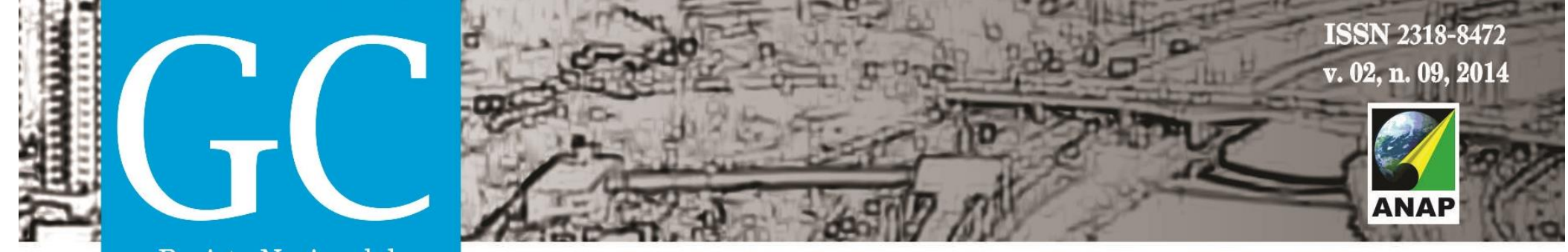

Revista Nacional de

Gerenciamento de Cidades

Figura 2 - Centro de Ituiutaba-MG: espacialização das rampas de acesso.

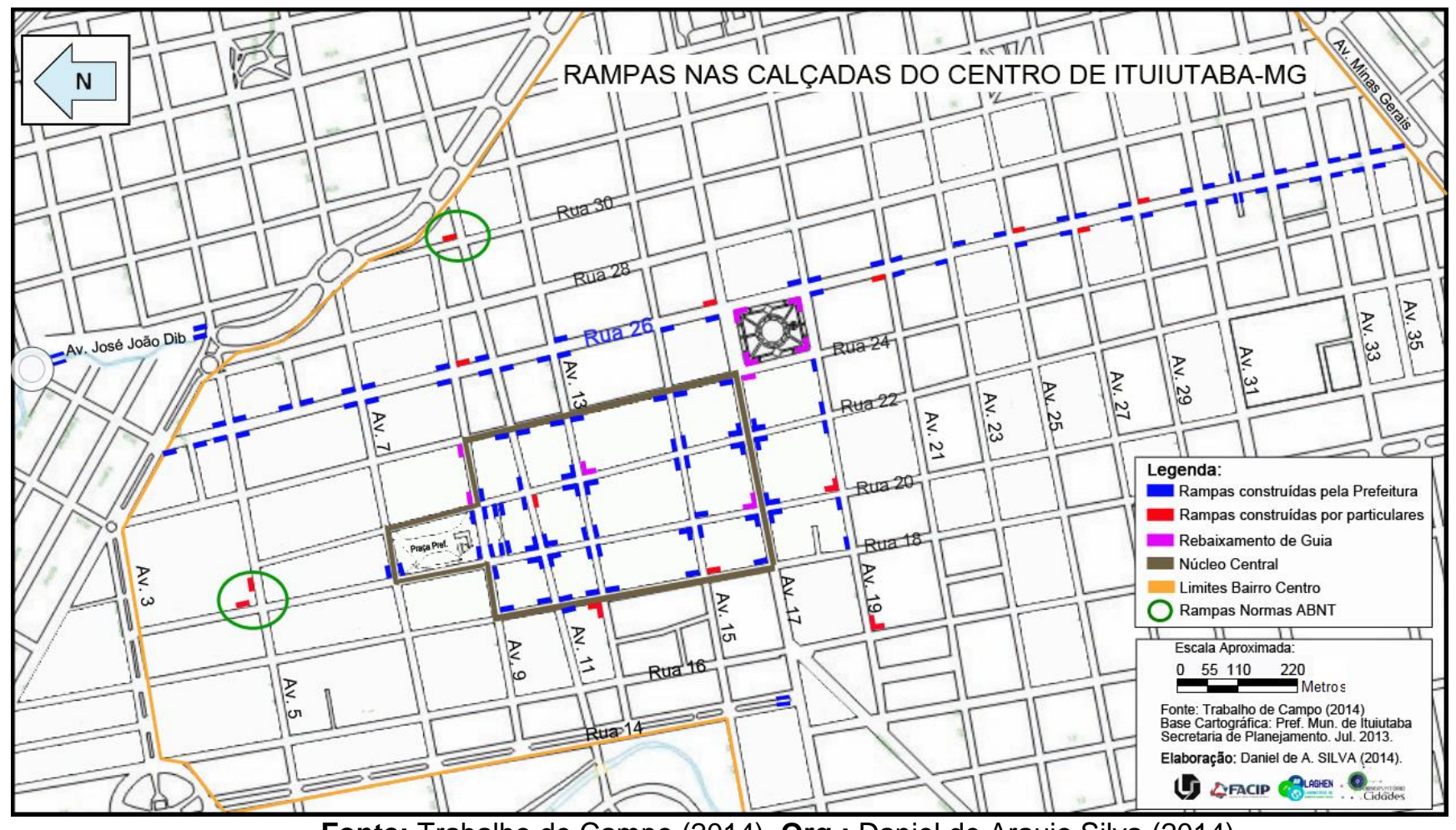

Fonte: Trabalho de Campo (2014). Org.: Daniel de Araujo Silva (2014). 

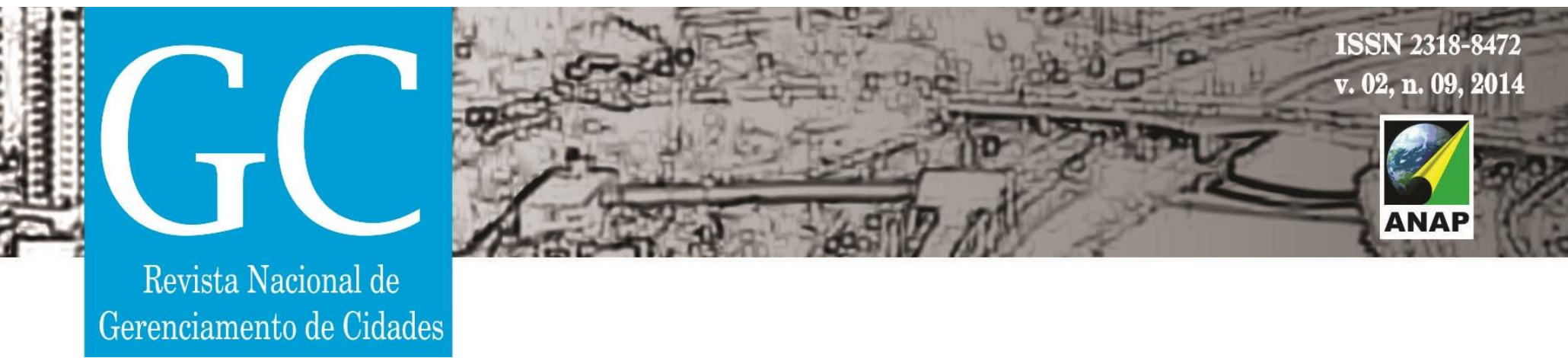

Conforme o mapeamento realizado, em todo o bairro centro foram identificados 164 pontos $^{3}$ com guias rebaixadas e rampas, considerando apenas os locais de cruzamento de via, sendo onze de calçadas e meio fio rebaixados, e 153 no formato de rampas. Em todos os cruzamentos das vias do núcleo central, para a circulação livre e sem interferências pelos cadeirantes, deveriam existir 180 pontos com a existência de rampas, no entanto foram identificados 82 pontos com a presença de rampas, ou seja, apenas 45,55\%. Foram identificados apenas quatro cruzamentos em que todos os pontos existem rampas, nos outros locais, os pontos não estão completos, o que dificulta a travessia e o acesso à calçada.

A função das rampas consiste no auxílio ao cadeirante em sua circulação e acesso à cidade. Mas a maioria delas acaba dificultando ainda mais seu deslocamento, devido as condições destas rampas, visto que nenhuma encontrada contempla os requisitos básicos recomendados nos padrões e normas da ABNT, não possuem a largura mínima exigida de 1,20 m, todas estão abaixo de 1,00 m, de acordo com as medições in loco. Observamos alguns problemas em inúmeras rampas, por exemplo, a existência de barreira (Figura 3A), que obstrui a passagem destinada ao cadeirante. A falta de manutenção é um agravante das más condições das rampas, algumas estão quebradas ou carcomidas em sua base, desta forma a cadeira tende a travar e não consegue subir. Mas ainda existem outras que de tão deterioradas e/ou totalmente quebradas, nem se parecem mais com uma rampa (Figura 3B). Contudo, a maioria das rampas possui algum tipo de problema além dos já citados, como: inclinação e largura bem abaixo das recomendadas; sem sinalização tátil de alerta e sem abas laterais; e em descontinuidade, ou seja, nem sempre apresentando rampas de um lado e de outro na continuidade da faixa (Figura 3C).

\footnotetext{
${ }^{3}$ Nos referimos a PONTOS cada lado da guia, sendo estas localizadas no Início/Fim da faixa de pedestre.
} 


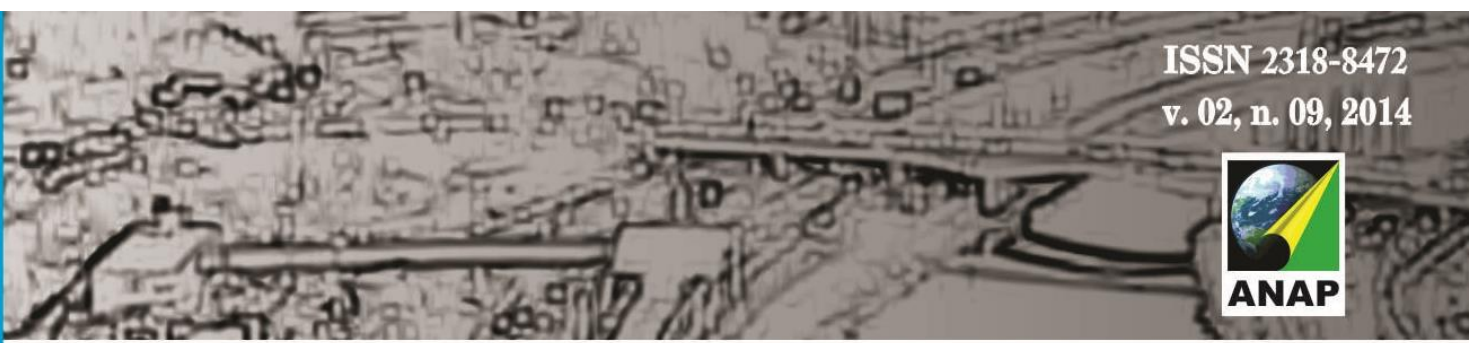

Revista Nacional de

Gerenciamento de Cidades

Figura 3 - Rampas de Acesso no centro: condições estruturais.

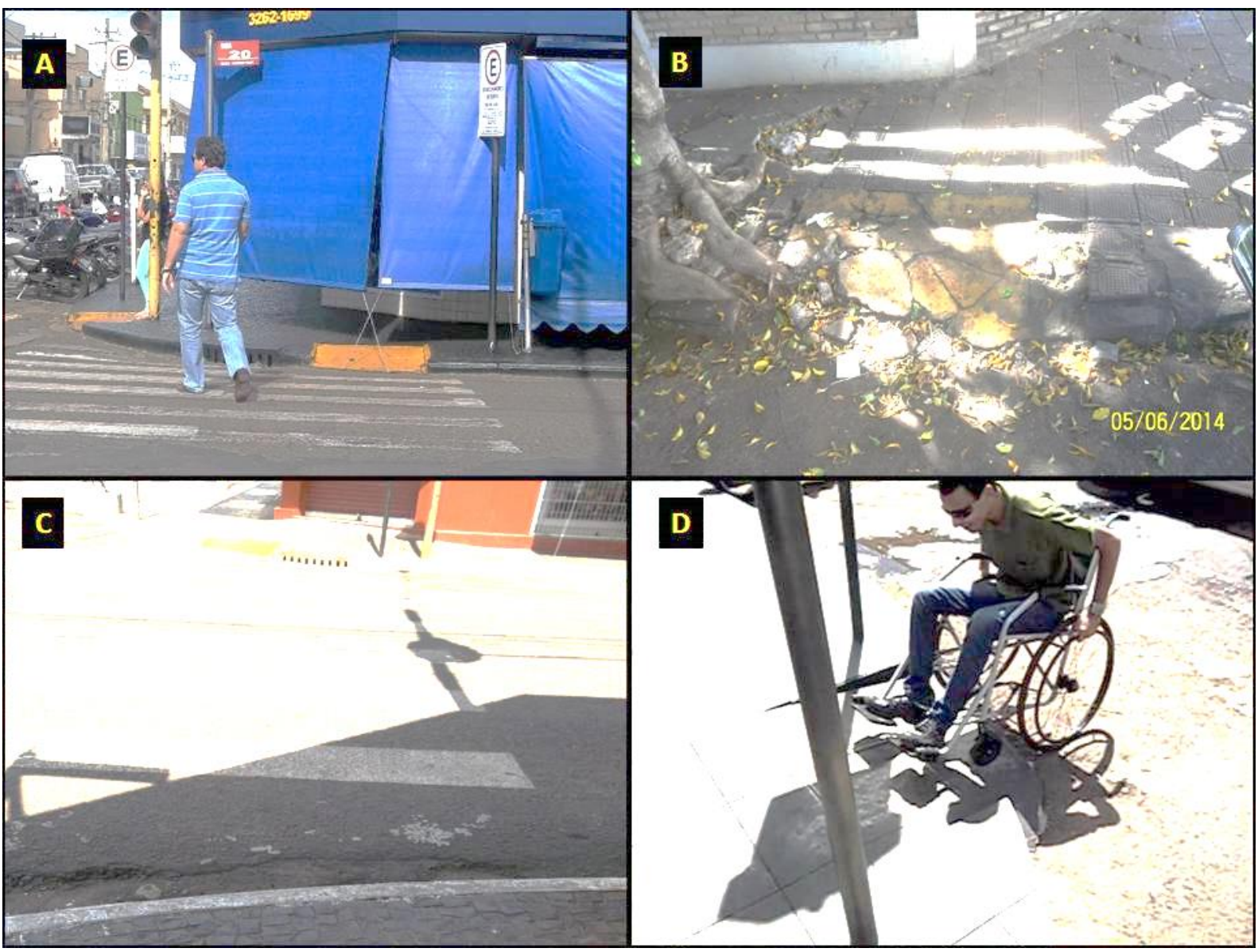

Fonte: Trabalho de Campo (2013/2014). Org.: Daniel de Araujo Silva (2014).

Podemos notar pelas imagens da figura 3 que os rebaixamentos não seguem um padrão, nem de recomendações técnicas e nem de modelos. A este último notamos que na maioria dos casos o proprietário da calçada quando reforma a mesma como forma de estética aplica à rampa e o faz de qualquer modo, também não seguindo nenhum padrão. Ou seja, assim nenhum dos exemplos facilita o trânsito dos usuários.

As imagens evidenciam as dificuldades de um cadeirante em utilizar a rampa (Figura 3D). Primeiro pelo formato e suas condições, o que dificulta o ingresso da 

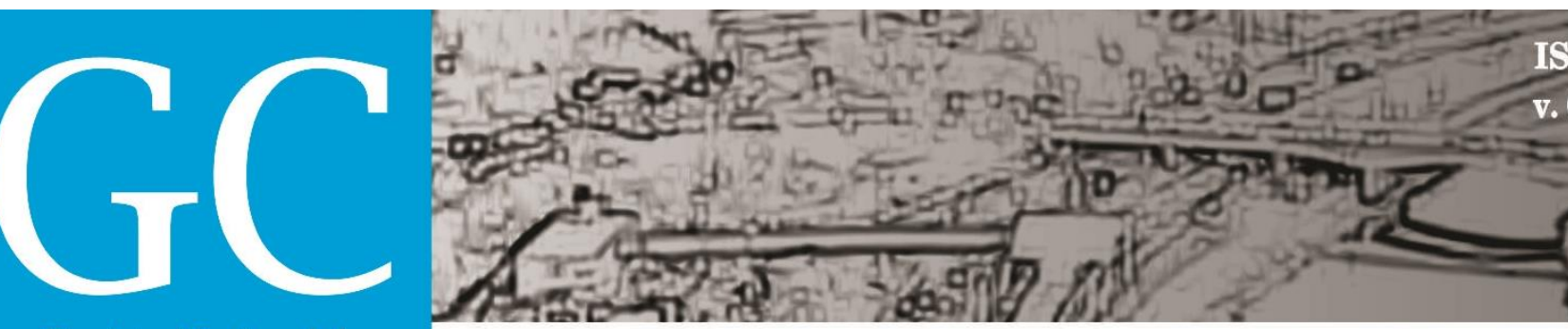

Revista Nacional de

Gerenciamento de Cidades

cadeira, e segundo, por sua inclinação a roda desliza sobre a elevação, forçando o cadeirante a impor uma força extra em seu movimento para transpor a dificuldade. Desta forma, as imagens deixam transparecer que as rampas foram instaladas apenas para cumprir uma pseudo "obrigação social". Entretanto, não prezou pelas normas de utilização para um deslocamento sem transtornos, como consta no PDI.

Com o mapeamento é possível notar um contínuo que ocorre na Rua 26, na qual foram implantadas rampas ao longo de sua extensão, algumas rampas, diferentemente do núcleo central, possuem o símbolo internacional de acesso (Figura 4A), mas também não seguem os padrões da ABNT em nenhum outro aspecto.

Dentre os problemas identificados nestes locais, o que chama mais atenção é quanto a localização das rampas, visto que somente foram implantadas no lado da Rua 26, no lado das outras ruas que fazem cruzamento não foram construídas nenhuma rampa. Ainda, quanto ao local, em apenas dois cruzamentos as rampas estão em concordância com as faixas de pedestre, no restante estão descontínuas. Muitas rampas foram feitas dentro do limite de estacionamento regulamentado da via (Figura 4B), ou seja, é fácil flagrar veículos estacionados de fronte as rampas, mas a própria prefeitura que faz a marcação do limite de estacionamento, e por sinal de forma errada, indiretamente incentiva o bloqueio às rampas. As rampas são feitas ignorando as normas, em alguns casos algumas "absurdos" são construídos (Figura 4C), ao invés da sinalização tátil, uma elevação acima do nível do passeio é colocada na rampa, podendo causar algum tropeço por quem passar por ali, os deficientes visuais são potenciais vítimas destas obras mal executadas e/ou planejadas. 

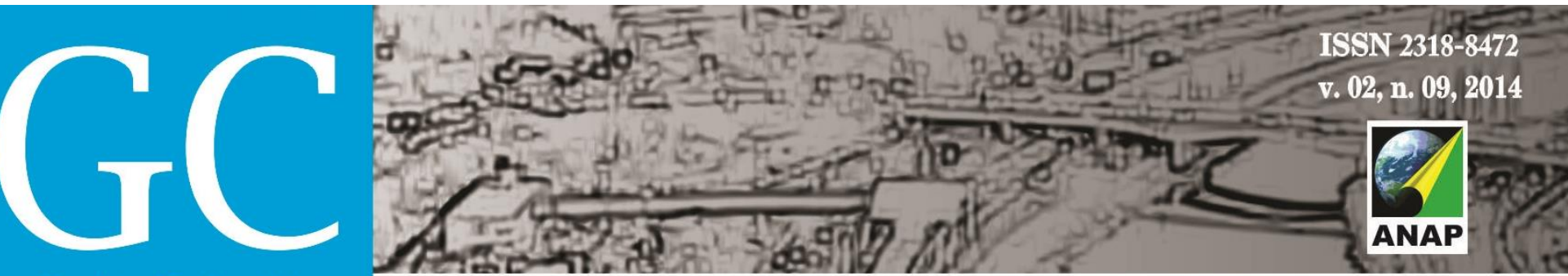

Revista Nacional de Gerenciamento de Cidades

Figura 4 - Rampas da Rua 26: outros modelos, problemas iguais.

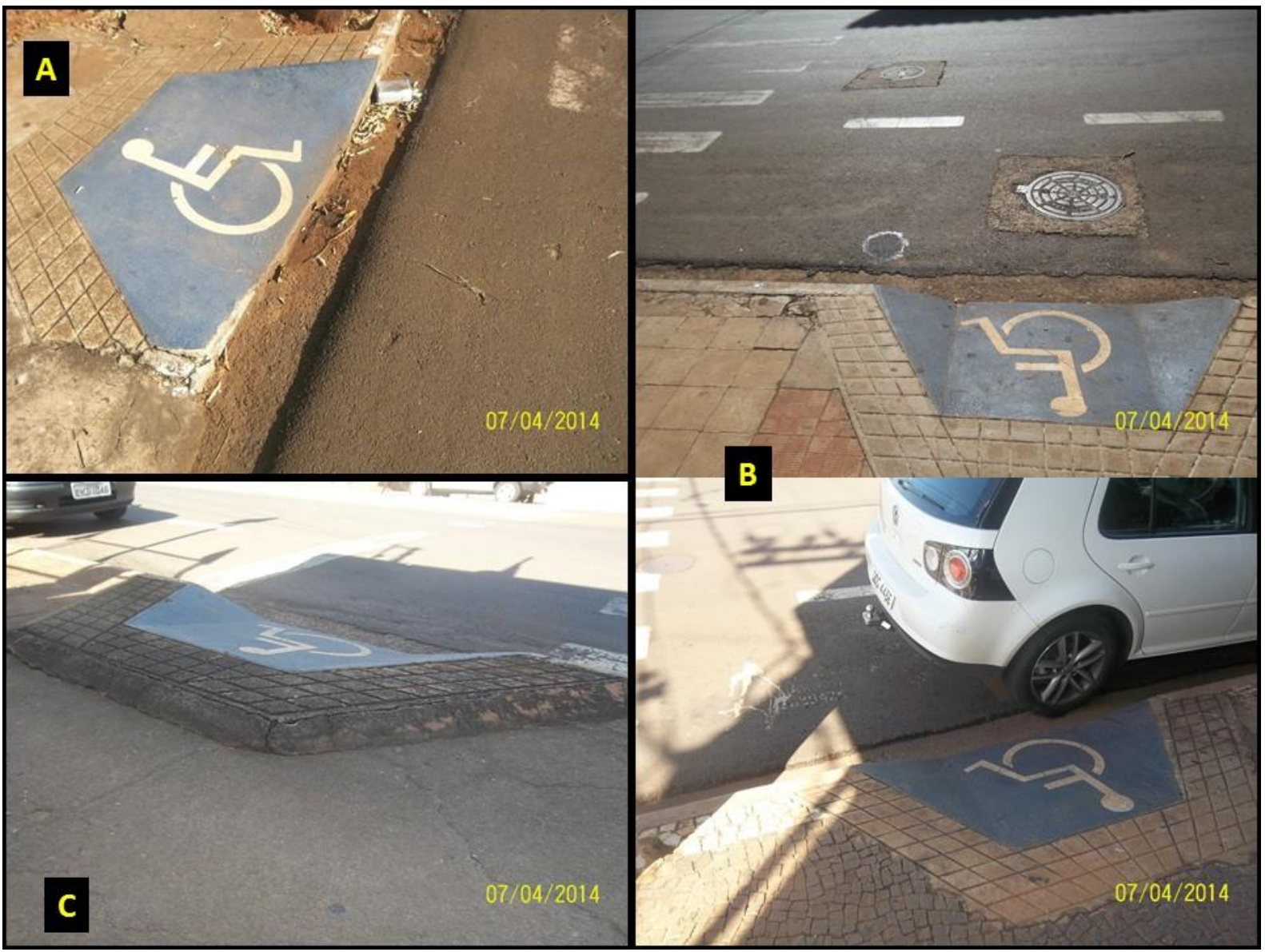

Fonte: Trabalho de Campo (2014). Org.: Daniel de Araujo Silva (2014).

Do universo das rampas por nós analisadas, apenas duas estão de acordo com as normas ABNT (Figura 5), pelo mesmo no quesito da construção das mesmas. Estas não foram construídas pela prefeitura, possuindo as medidas corretas, abas laterais e com sinalização tátil. Já na figura $5 \mathrm{~A}$, o problema está na localização, foram feitas fora da faixa de pedestre. A rampa da figura 5B é de um modelo diferente de rampa, utilizado em locais onde as calçadas são mais estreitas, sendo a mesma toda rebaixada, esta em particular, foi construída para atender os cadeirantes que estacionam no INSS, daí o motivo dela não estar na faixa de pedestres. 

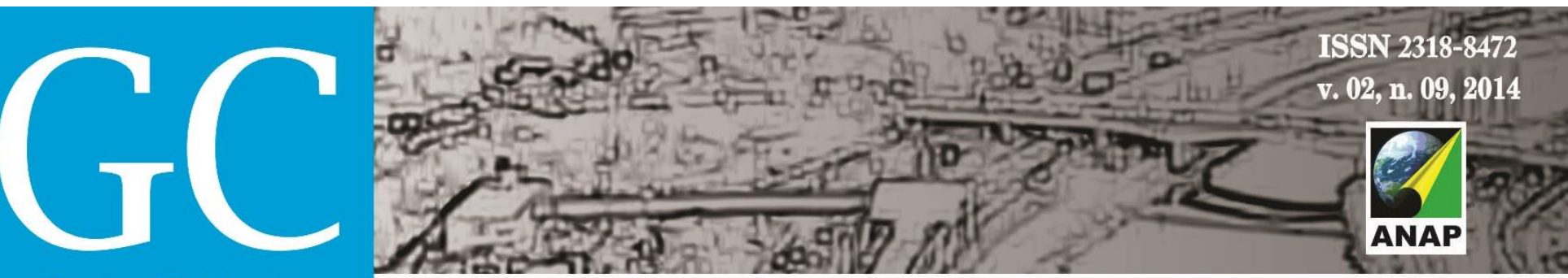

Revista Nacional de

Gerenciamento de Cidades

Figura 5 - Rampas construídas de acordo com as normas ABNT.

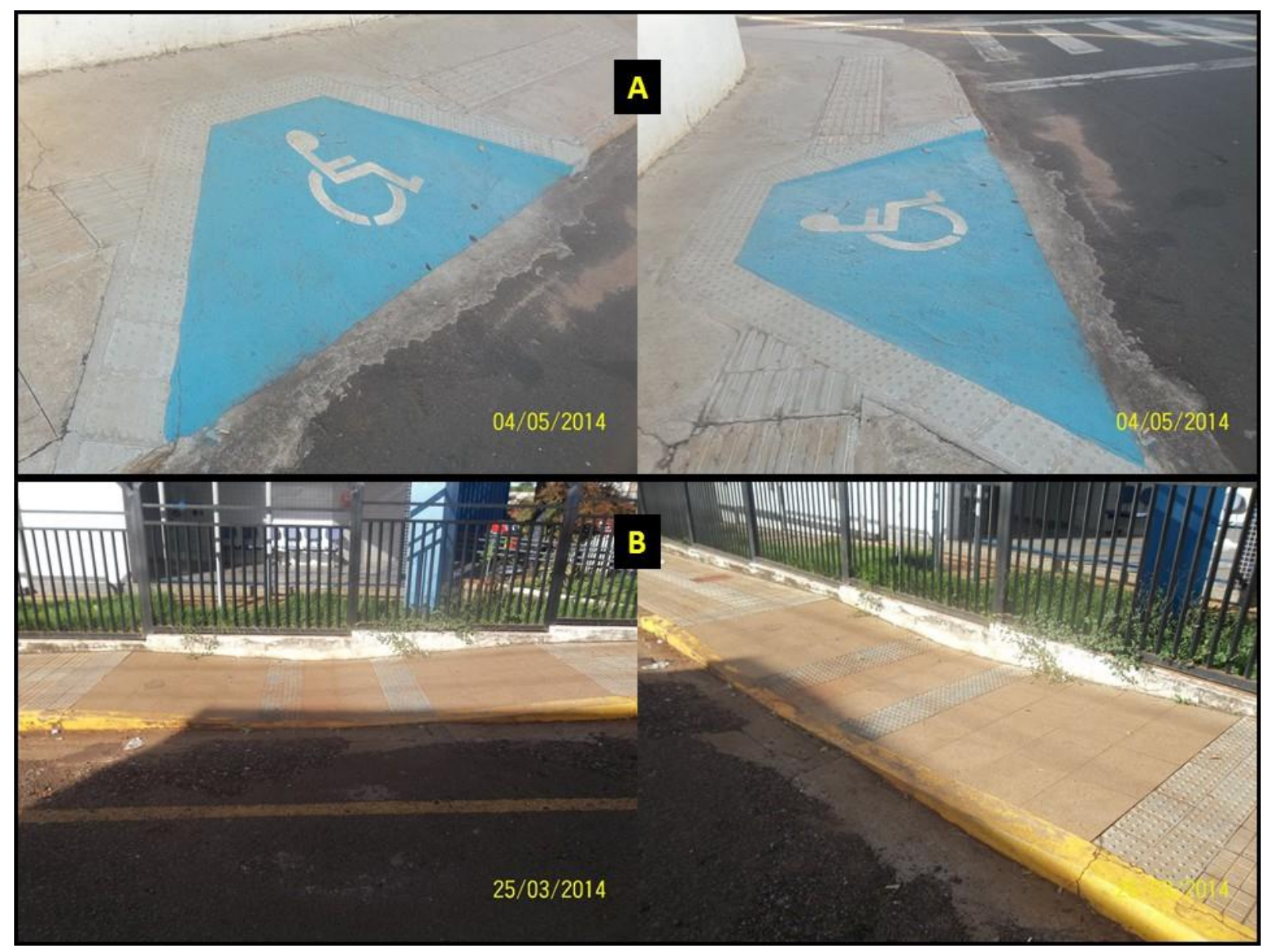

Fonte: Trabalho de Campo (2014). Org.: Daniel de Araujo Silva (2014).

Resumindo, de forma geral as rampas de Ituiutaba não seguem as normas e os padrões recomendados pela ABNT, sua implantação é aleatória, em cada esquina é feita de um jeito, com pisos diferenciados, com inclinações e medidas diferentes, em locais inapropriados e sem a sinalização tátil. Também é possível notar, que em algumas esquinas, de um lado da rua existe a rampa, mas do outro lado a mesma inexiste, não fazendo sentido algum, de forma que não compreendemos esta atitude, pois, a implantação das rampas deve ser feita aos 

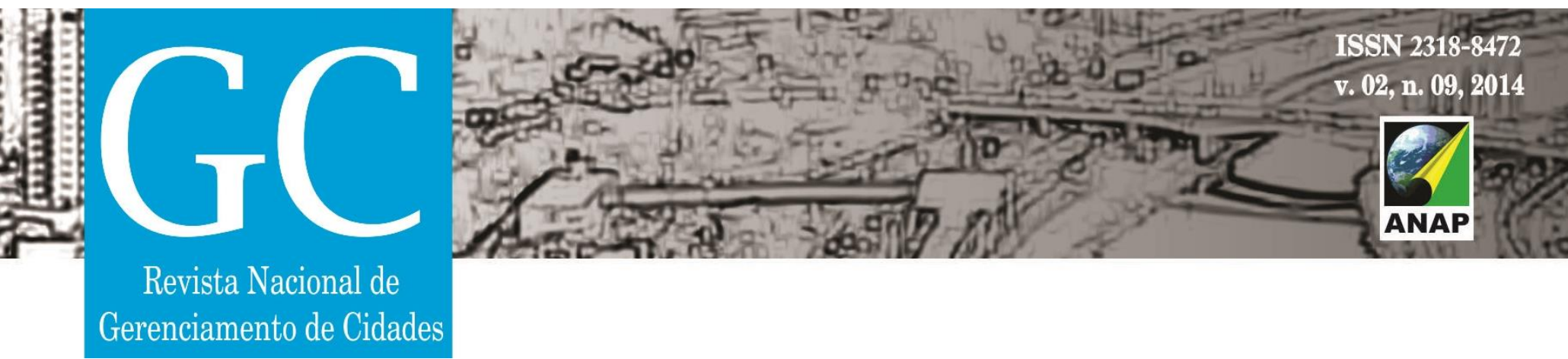

pares, tanto de um lado como de outro da via. A prefeitura deveria aproveitar as novas obras e reformas para realizar a construção adequada, de acordo com as normas promovendo assim a acessibilidade no município, mas isso não ocorre, tanto em novas construções quanto em reformas não existe essa preocupação, sendo totalmente ignoradas.

\section{CONCLUSÃO}

Em relação aos instrumentos de acessibilidade nas vias e áreas públicas podemos inferir através desta pesquisa, que não existe uma preocupação do poder público municipal devida para com a acessibilidade em Ituiutaba, o que é lamentável, considerando a cidade no início do século XXI. Isto pelo fato de que devemos pensar a circulação das pessoas de forma ampla e, por isso mesmo, de forma universal, ou seja, todo tipo de pessoa exercendo práticas socioespaciais. No entanto, nossa reflexão aponta para uma realidade em que nem todas as pessoas, ou ao menos, boa parte delas, conseguem deslocar-se com segurança e independência, sobretudo, as pessoas com algum tipo de mobilidade reduzida.

O resultado não é satisfatório e o descaso acompanha essa constatação, nem todas as esquinas e cruzamentos possuem rampas de acesso ou guias rebaixadas, ocorrendo uma descontinuidade. Em nenhuma delas encontramos sinalização tátil, e a maioria não está em conformidade com as faixas de pedestres, além de não seguirem nenhum padrão e normas recomendadas pela ABNT, e a maioria delas se encontram péssimas em condições estruturais. Assim, o que era para dar acesso na maioria das vezes impossibilita o acesso dos cadeirantes à cidade. Se no centro da cidade a acessibilidade é inexistente, imaginemos a situação das pessoas que necessitam deste direito nos bairros periféricos.

Do ponto de vista da legalidade, constatamos que as leis existem, as normas são estabelecidas, portanto, o que falta para que o direito de acessibilidade seja 
Revista Nacional de

Gerenciamento de Cidades

cumprido? O poder público municipal tem amparos legais, cartilhas, guias, dentre outros materiais, para criar instrumentos que possibilite uma política de acessibilidade na cidade.

\section{REFERÊNCIAS}

ABNT - Associação Brasileira de Normas Técnicas. NBR-9050: Acessibilidade a edificações, mobiliário, espaços e equipamentos urbanos. Rio de Janeiro: ABNT, 2004.

BRASIL. Cartilha da mobilidade urbana. Mobilidade urbana é desenvolvimento urbano! Ministério das Cidades. 2. ed. Brasília-DF, 2005.

Construindo uma Cidade Acessível. Caderno 2. Ministério das Cidades. Brasília - DF. (2006). Disponível em:

<http://www.cidades.gov.br/images/stories/ArquivosSEMOB/Biblioteca/BrasilAcessivelCaderno02.pdf >. Acesso em: 03 Nov. 2013.

Lei no 12.587, de 03 de janeiro de 2012. Institui a Política Nacional de Mobilidade Urbana. Diário Oficial da União, Brasília DF, 3 jan. 2012. Disponível em:

<http://www.planalto.gov.br/ccivil_03/_ato2011-2014/2012/lei/12587.htm>. Acesso em: 10

Out. 2012.

CORRÊA, Roberto Lobato. O espaço urbano. 4. ed. São Paulo: Ática. 2005.

LEFEBVRE, Henri. A revolução urbana. Tradução: Sergio Martins. Belo Horizonte: Editora UFMG, 1999, $178 \mathrm{p}$.

O direito a cidade. São Paulo: Centauro, 2001.

CARLOS, Ana Fani Alessandri. Espaço-tempo na metrópole: fragmentação da vida cotidiana. São Paulo: Contexto, 2001.

O Espaço Urbano: Novos Escritos sobre a Cidade. São Paulo: FFLCH, 2007, 123p.

DUARTE, Fábio; LIBARDI, Rafaela; SÁNCHEZ, Karina. Introdução à mobilidade urbana. $1^{\text {a }}$ Ed. (2007), 2ª Reimpr. Curitiba: Juruá, 2011. 108 p.

LOBODA, Carlos Roberto. Práticas socioespaciais e espaços públicos em Guarapuava-PR. 2008. 337f. Tese (Doutorado em Geografia) Universidade Estadual Paulista, campus de Presidente Prudente, 2008.

MOREIRA, Diego Henrique; RIBEIRO FILHO, Vitor; ALVES, Lidiane Aparecida. Os instrumentos de acessibilidade na cidade de Araguari-MG. In: FILHO, Vitor Ribeiro; ALVES, Lidiane Aparecida (Org's). Reflexões Geográficas: diferentes leituras sobre o urbano. Uberlândia: Edibrás, 2012. 300 p. 

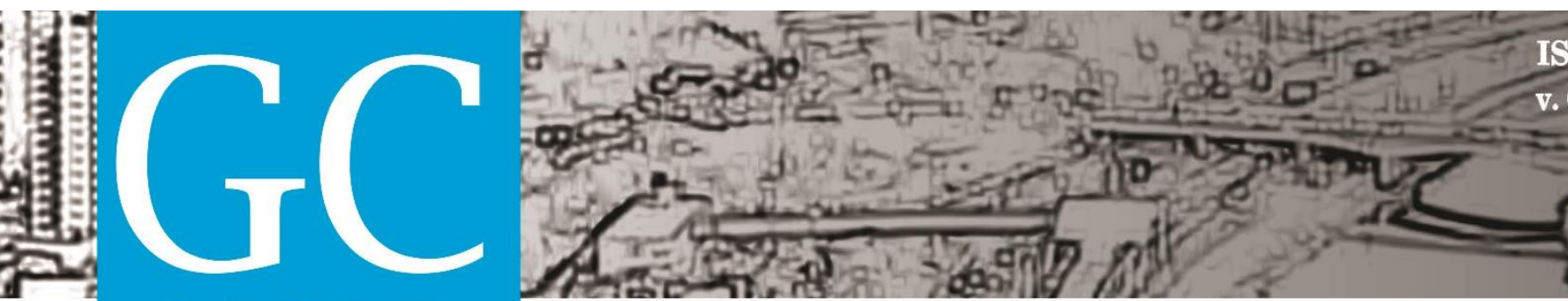

Revista Nacional de

Gerenciamento de Cidades

NARCISO, Carla Alexandra Filipe. Espaço público: ação política e práticas de apropriação. Conceitos e procedências. Estudos e Pesquisas em Psicologia: UERJ, Rio de Janeiro, v. 9, n. 2, p.265-291, 2009. Disponível em: <http://www.revispsi.uerj.br/v9n2/artigos/pdf/v9n2a02.pdf>. Acesso em: 01 Set. 2013.

RIBEIRO FILHO, Vitor; ALVES, Priscilla; ALVES, Lidiane Aparecida. Mobilidade e acessibilidade urbana com foco nas pessoas com mobilidade reduzida. In: RIBEIRO FILHO, Vitor; ALVES, Lidiane Aparecida (Org's). Reflexões Geográficas: diferentes leituras sobre o urbano. Uberlândia: Edibrás, 2012. p. $165-174$.

SANTOS, F. O. Acessibilidade: um desafio para as cidades saudáveis. In: RIBEIRO FILHO, Vitor; ALVES, Lidiane Aparecida (Org's). Reflexões Geográficas: diferentes leituras sobre o urbano. Uberlândia: Edibrás, 2012. p. 175 - 188.

SANTOS, Milton. O espaço do cidadão. 7 ed. São Paulo: EDUSP, 2007.

TEIXEIRA, Suellen Carvalho; OLIVEIRA, Hélio Carlos Miranda de. A Conformação do Núcleo Central de Ituiutaba-MG. Relatório de Iniciação Científica (FAPEMIG). 2011.

VASCONCELLOS, E. A. Transporte urbano, espaço e equidade. São Paulo: FAPESP, 1996. 